\title{
Kidney Lobe
}

National Cancer Institute

\section{Source}

National Cancer Institute. Kidney Lobe. NCI Thesaurus. Code C32894.

A functional unit of the kidney consisting of a renal pyramid and the renal cortex surrounding it. 